\begin{tabular}{c|c}
\hline NAR & $\begin{array}{c}\text { Management and Business Review } \\
\text { Available at http://ejournal.unikama.ac.id/index.php/mbr } \\
\text { ISSN: 2541-5808 (online) } \\
\text { BUSINESSRENTEW }\end{array}$ \\
\hline
\end{tabular}

\title{
Pengaruh harga dan lokasi terhadap keputusan pembelian produk jasa
}

\author{
Suratmiyati ${ }^{1}$, Yudhi Anggoro ${ }^{2}$ \\ 1,2Program Studi Manajemen, STIE Indocakti Malang, Indonesia \\ e-mail: amy_dh18@ymail.com
}

\begin{tabular}{|c|c|}
\hline \multicolumn{2}{|c|}{ Article Info: } \\
\hline Receive & : Juni 2020 \\
\hline Revised & : Juli 2020 \\
\hline Accepted & : Juli 2020 \\
\hline Published & : Juli 2020 \\
\hline DOI & : 10.21067/mbr.v4i1.4629 \\
\hline Copyright & $\begin{aligned}: \text { Management and } \\
\text { Business Review }\end{aligned}$ \\
\hline
\end{tabular}

Keywords:

Price, Location, Purchasing Decision, Marketing

\begin{abstract}
The aims of this study to determine the effect of price and location on service product purchasing decisions at Villa Victoria Boutique Residences Malang. The research method used quantitative descriptive, nonprobability sampling with accidental sampling method. This research was conducted on Villa Victoria Boutique Residences consumers with a sample size of 87 respondents. Measurement of the variables in this study was carried out using a Likert scale. The analysis technique uses Multiple Linear Regression analysis. The results showed that partially the price did not have a significant effect on purchasing decisions, while location had a significant effect on purchasing decisions.
\end{abstract}

\begin{abstract}
Abstrak: Penelitian bertujuan untuk mengetahui pengaruh harga dan lokasi terhadap keputusan pembelian produk jasa di Villa Victoria Boutique Residences Malang. Metode penelitian menggunakan deskriptif kuantitatif, pengambilan sampel non probability sampling dengan metode accidental sampling. Penelitian ini dilakukan pada konsumen Villa Victoria Boutique Residences dengan jumlah sampel sebanyak 87 responden. Pengukuran terhadap variable-variabel dalam penelitian ini dilakukan dengan menggunakan skala Likert. Teknik analisis menggunakan analisis Regresi Linear Berganda. Hasil penelitian menunjukkan bahwa secara parsial harga tidak berpengaruh signifikan terhadap keputusan pembelian, sedangkan lokasi berpengaruh signifikan terhadap keputusan pembelian.
\end{abstract}




\section{Pendahuluan}

Villa Victoria Boutique Residences Malang merupakan penginapan yang masih baru diresmikan pada bulan Mei 2018, dimana sebelumnya merupakan bangunan yang akan digunakan untuk pertokoan, namun karena perkembangan kota Malang yang semakin meningkat pertumbuhan bidang pariwisata maka pemilik berubah tujuan dari pertokoan menjadi penginapan. Villa Victoria Boutique Residence adalah penginapan baru dengan konsep boutique hotel dengan desain arsitektur kolonial dipadukan dengan sentuhan detil budaya lokal yang berada di pusat Kota Malang atau tepatnya berada di Jalan Ciujung No. 7 Kecamatan Blimbing, sehingga sangat mudah dijangkau karena letaknya tidak jauh dari jalan protokol.

Beberapa faktor mempengaruhi keputusan pembelian suatu produk, salah satunya adalah harga, harga mempengaruhi keputusan konsumen dalam melakukan pembelian, karena daya beli atau pendapatan yang dimiliki, macam dari barang, serta pelayanan suatu produk (Hasan, 2009).

Harga adalah suatu nilai yang dinyatakan dengan uang, dan merupakan salah faktor yang menentukan pengambilan keputusan pelanggan, sementar harga akan ditentukan oleh biaya produksi dari suatu produk (Alma, 2011). Apabila harga yang ditawarkan dapat sesuai dengan harapan pelanggan, akan menyebabkan pelanggan loyal. Harga merupakan sejumlah uang (ditambah beberapa barang) yang dibutuhkan untuk memperoleh sejumlah kombinasi barang dan pelayanan (Swastha \& Sukotjo, 2010).

Keberhasilan perusahaan memasarkan barang atau jasa, ditentukan oleh kebijakan harga yang tepat. Unsur bauran pemasaran yang memberikan pemasukan atau pendapatan bagi perusahaan, sedangkan ketiga unsur lainnya berupa produk, distribusi, dan promosi membutuhkan pengeluaran dana (Tjiptono \& Chandra, 2011). Dalam iklim persaingan yang ketat seperti sekarang ini, perusahaan harus memperhatikan faktor harga, karena besar kecilnya harga yang ditetapkan akan sangat mempengaruhi kemampuan perusahaan dalam bersaing dan juga mampu mempengaruhi konsumen untuk membeli produknya (Swastha \& Sukotjo, 2010)..

Keputusan pemilihan lokasi berkaitan dengan komitmen jangka panjang terhadap aspek-aspek yang sifatnya kapital insentif, karena itu perusahaan mempertimbangkan, menyeleksi dan memilih lokasi yang responsif terhadap kemungkinan perubahan ekonomi, demografis, budaya, persaingan dan peraturan di masa yang akan datang (Tjiptono \& Chandra, 2011).

Faktor lokasi hotel sangat berpengaruh pada pemilihan tempat menginap di hotel oleh para konsumen. Selain akses yang mudah, lokasi hotel yang berada di pusat kota menawarkan banyak destinasi wisata belanja sambil menikmati keindahan kota menjadi nilai lebih bagi hotel. 
Tujuan penelitian ini adalah menganalisis pengaruh harga dan okasi terhadap keputusan pembelian produk jasa di villa victoria boutique residences malang.

Penelitian terbaru dari Gultom (2020) yang melakukan penelitian pada Quality Fried Chicken menemukan hasil bahwa harga dan lokasi menjadi pertimbangan konsumen dalam pengambilan keputusan pembelian Quality Fried Chicken. Hasil tersebut mendukung penelitian sebelumnya yang menyatakan bahwa keputusan pembelian dipengaruhi oleh inovasi produk dan harga (Al Rasyid \& Indah, 2018), dipengaruhi oleh kualitas layanan, produk dan harga (Adipramita, 2019), dipengaruhi oleh kualitas produk, harga, dan lokasi (Rofiq \& Hufron, 2018). Demikian juga dari hasil penelitian (Wihara, 2017) dan (Harjanto, 2016) menyatakan bahwa keputusan pembelian dipengaruhi oleh harga dan lokasi. Namun hasil yang berbeda dari penelitian Setyarko (2016) dan Nurhayati (2017) yang menyatakan bahwa harga tidak berpengaruh terhadap keputusan pembelian.

Berdasarkan beberapa penelitian terdahulu, maka disusun model kerangka konseptual dan hipotesis sebagai berikut :

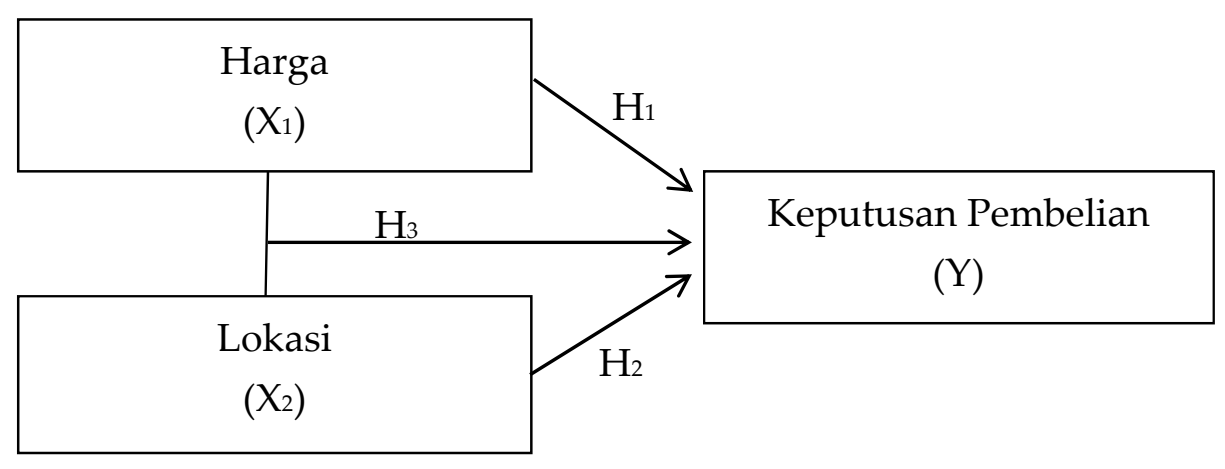

\section{Gambar 1. Kerangka Konseptual}

Berdasarkan permasalahan dan kerangka pemikiran, maka hipotesis yang diajukan dalam penelitian ini adalah:

H1 : Terdapat pengaruh positif harga terhadap keputusan pembelian.

H2 : Terdapat pengaruh positif lokasi terhadap keputusan pembelian.

H3 : Terdapat pengaruh positif harga dan lokasi terhadap keputusan pembelian.

\section{Metode}

Jenis penelitian adalah deskriptif kuantitatif, dimana peneliti melakukan penelitian ilmiah yang sistematis terhadap bagian-bagian dan fenomena yang terjadi dilapangan. Tujuan penelitian dituangkan dalam hipotesis yang selanjutnya diuji kebenarannya dengan statistik yaitu dengan menggunakan SPSS dan mengambil 
sampel dari satu populasi dan menggunakan kuisioner sebagai alat pengumpulan data yang pokok. Penelitian dilakukan pada Villa Victoria Boutique Residences Malang. Populasi penelitian ini adalah tamu pada Villa Victoria Boutique Residences, teknik pengambilan sampel dengan accidental sampling yaitu metode penentuan sampel atas dasar kebetulan yaitu siapa pun yang kebetulan bertemu dengan peneliti bisa digunakan sebagai sampel, jika rasa orang yang kebetulan ditemui tersebut cocok digunakan sebagai sumber data. Sampel penelitian ini ditentukan sebanyak 87 orang tamu pada Villa Victoria Boutique Residences Malang selama periode penelitian.

Agar dapat menganalisa dan menginterprestasikan data dengan baik diperlukan data yang valid dan reliable, agar hasil yang didapat mengandung kebenaran. Data penelitian dikumpulkan dengan penyebaran kuisioner pada sampel tamu Villa Victoria Boutique Residences Malang. Kuisioner yang diserahkan pada responden adalah suatu bentuk kuisioner terstruktur, yaitu suatu kuisioner dimana daftar pertanyaan sudah disiapkan sebelumnya, responden diminta menjawab pilihan jawaban yang tersedia.

Variabel penelitian terdiri dari variabel dependent yaitu keputusan pembelian (Y), dan variabel independent meliputi harga (X1) dan lokasi (X2). Skala yang digunakan adalah Skala Likert yang digunakan untuk mengukur sikap pendapat dan persepsi seseorang atau sekolompok orang tentang fenomena sosial (Sugiyono, 2011). Pengukuran terhadap variable harga dan lokasi $(X)$ dan keputusan pembelian (Y), dilakukan dengan menggunakan Skala Likert 5 point, mulai 1 sampai dengan 5, yang dapat dirinci sebagai berikut : Sangat Tidak Setuju (TS) skor 1, Tidak Setuju (KS) skor 2, Ragu-Ragu (RR) skor 3, Setuju (S) skor 4, Sangat Setuju (SS) skor 5

Metode analisa data yang digunakan pada penelitian ini adalah metode statistik deskriptif dan Analisis Regresi Berganda, bentuk umum persamaan regresi linear berganda (Sarwoko, 2018) sebagai berikut :

$\mathrm{Y}=\mathrm{a}+\mathrm{b} 1 \mathrm{X} 1+\mathrm{b} 2 \mathrm{X} 2+\mathrm{e}$

Dimana :

Y adalah variabel terikat ( Keputusan Pembelian)

b1, b2 adalah koefisien regresi

$\mathrm{X} 1$ : harga

X2: lokasi

e: kesalahan pengganggu (disturbance term)

Semua analisis dilakukan dengan menggunakan SPSS-18 yaitu program pengolahan data untuk menguji data-data yang diperoleh. 


\section{Hasil}

\section{Analisis Regresi Berganda}

Analisis data menggunakan Regresi Linier Berganda, digunakan untuk menguji besarnya pengaruh perubahan variabel bebas terhadap perubahan variabel terikat. Hasil analisis Regresi disajikan pada tabel 1.

Tabel 1

Analisa Regresi Berganda

\begin{tabular}{ccccl}
\hline Variabel & $\mathrm{b}$ & $\mathrm{t}$ & Sig. & Keterangan \\
\hline Harga & -0.068 & -0.469 & 0.642 & Tidak signifikan \\
Lokasi & 1.085 & 6.687 & 0.000 & Signifikan \\
\hline $\mathrm{F}$ & 33.061 & & & \\
Sig. & 0.000 & & & \\
$\mathrm{R}^{2}$ & 0.641 & & & \\
\hline
\end{tabular}

Sumber: Data diolah.

Hasil analisis Regresi Linier berganda menunjukkan bahwa pada variabel harga menunjukkan tingkat signifikasi 0,642, hal ini berarti bahwa keputusan pembelian tidak dipengaruhi oleh variabel harga yang ditetapkan oleh Villa Victoria Boutiques Malang dengan asumsi variabel lokasi dianggap konstan. Pada variabel lokasi menunjukkan tingkat signifikasi 0,000, hal ini menunjukkan bahwa keputusan pembelian akan meningkat dengan asumsi variabel harga dianggap konstan.

Nilai R Square menunjukkan nilai koefisien determinasi sebesar 0,641 atau $64,1 \%$, artinya bahwa harga dan lokasi berpengaruh terhadap keputusan pembelian sebesar $64,1 \%$, sedangkan sisanya sebesar $35,9 \%$ dipengaruhi oleh variabel-variabel lain yang tidak di uji pada penelitian ini.

\section{Hasil Uji Hipotesis 1:}

Berdasarkan hasil analisis data pada tabel 1 , diperoleh hasil $t$-test untuk variabel harga dengan tingkat signifikansi 0,642 lebih besar dari $0.05(\alpha=5 \%)$ artinya bahwa variabel harga secara siginifikan berpengaruh positif terhadap keputusan pembelian, dengan demikian hipotesis 1 ditolak.

\section{Hasil Uji Hipotesis 2:}

Berdasarkan hasil analisis data pada tabel 1, diperoleh hasil $t$-test untuk variabel lokasi dengan tingkat signifikansi 0,000 lebih kecil dari $0.05(\alpha=5 \%)$ artinya bahwa variabel lokasi secara siginifikan berpengaruh positif terhadap keputusan pembelian, dengan demikian hipotesis 2 diterima. 


\section{Hasil Uji Hipotesis 3:}

Berdasarkan hasil analisis data pada tabel 1, diperoleh hasil F-test dengan tingkat signifikansi 0,000 lebih kecil dari $0.05(\alpha=5 \%)$ artinya bahwa variabel harga dan lokasi secara siginifikan berpengaruh terhadap keputusan pembelian, dengan demikian hipotesis 3 diterima.

\section{Pembahasan}

Dari hasil pengujian hipotesis secara parsial, menunjukkan bahwa variabel harga tidak berpengaruh secara siginifikan terhadap keputusan pembelian, sedangkan variabel lokasi secara siginifikan berpengaruh positif terhadap keputusan pembelian. Dari hasil pengujian hipotesis secara simultan, menunjukkankan bahwa variabel harga dan variabel lokasi berpengaruh signifikan terhadap keputusan pembelian.

Hal ini sejalan dengan penelitian yang dilakukan oleh Puspa et al. (2017) yang meneliti pengaruh harga dan lokasi terhadap keputusan pembelian Perumahan Ciujung River Park Serang, Banten, dengan temuan bahwa harga mempengaruhi keputusan pembelian perumahan, lokasi juga berpengaruh terhadap keputusan pembelian perumahan. Perbedaan dengan penelitian saat ini adalah harga dalam penelitian tidak mempengaruhi keputusan pembelian, sedangan lokasi mempengaruhi keputusan pembelian. Hasil penelitian ini juga mendukung penelitian Rares \& Jorie (2015) tentang pengaruh harga, promosi, lokasi, citra merek dan kualitas produk terhadap keputusan pembelian jasa konsumen di toko dan bengkel Gaoel Manadotown Square yang menunjukkan hasil bahwa harga dan lokasi berpengaruh positif terhadap keputusan pembelian. Temuan penelitian juga mendukung penelitian sebelumnya bahwa harga dan lokasi menjadi pertimbangan konsumen dalam pengambilan keputusan pembelian (Gultom, 2020; Harjanto, 2016; Rofiq \& Hufron, 2018; Wihara, 2017), keputusan pembelian juga dipengaruhi oleh harga (Adipramita, 2019; Al Rasyid \& Indah, 2018).

\section{Simpulan}

Pada penelitian Pengaruh Harga Dan Lokasi Terhadap Keputusan Pembelian Produk Jasa Di Villa Victoria Boutique Residences Malang ini, dengan instrumen kuesioner dimana telah di uji melalui statistik dengan SPSS versi 18 maka dapat ditarik kesimpulan bahwa secara parsial harga tidak berpengaruh secara signifikan terhadap keputusan pembelian, sedangkan lokasi berpengaruh secara 
signifikan terhadap keputusan pembelian, sedangkan secara simultan, harga dan lokasi berpengaruh secara signifikan terhadap keputusan pembelian.

Hal ini berimplikasi sekaligus menjadi saran bagi obyek penelitian bahwa harga yang ditetapkan dapat diterima dengan baik oleh konsumen, hal ini menjadi nilai tambah tersendiri sehingga harus dipertahankan untuk semakin memajukan Villa Victoria Boutique Residences Malang. Indikator-indikator faktor lokasi di sini merupakan faktor yang sulit untuk diubah maupun ditingkatkan. Namun tetapi ada beberapa usaha yang dapat dilakukan hotel, seperti menyediakan shuttle car dengan rute tertentu yang menjadi fasilitas gratis bagi tamu hotel. Hal ini dapat membuat tamu hotel lebih mudah untuk mengunjungi tempat-tempat tertentu dan dapat menjadi faktor yang menarik minat beli calon konsumen.

\section{Daftar Pustaka}

Adipramita, V. (2019). Pengaruh Kualitas Pelayanan, Persepsi Harga, dan Lokasi Terhadap Keputusan Pembelian di Toko Perhiasan emas Lancar Jaya Sekaran Lamongan. Jurnal Ekonomi Manajemen, 4(1).

Al Rasyid, H., \& Indah, A. T. (2018). Pengaruh Inovasi Produk dan Harga Terhadap Keputusan Pembelian Sepeda Motor Yamaha di Kota Tangerang Selatan. Jurnal Perspektif, 16(1), 39-49.

Alma, B. (2011). Manajemen pemasaran dan pemasaran jasa. Bandung: Alfabeta.

Gultom, P. (2020). Pengaruh Ekuitas Merek, Harga dan Lokasi Terhadap Keputusan Pembelian Konsumen pada Quality Fried Chicken Jalan Ismaliyah Medan. Jurnal Manajemen Bisnis Eka Prasetya: Penelitian Ilmu Manajemen, 6(1), 44-53.

Harjanto, D. (2016). Pengaruh Harga dan Lokasi Terhadap Keputusan Pembelian Rumah Pada CV. Interhouse Design. Jurnal Manajemen Dan Start-Up Bisnis, 1(3), $1-5$.

Hasan, A. (2009). Marketing. Media Presindo.

Nurhayati, S. (2017). Pengaruh citra merek, harga dan promosi terhadap keputusan pembelian handphone samsung di yogyakarta. Jurnal Bisnis, Manajemen, Dan Akuntansi, 4(2).

Puspa, R., Permana, A., \& Nuryanti, S. (2017). Pengaruh Harga dan Lokasi Terhadap Keputusan Pembelian (Studi Kasus pada Perumahan Ciujung River Park Serang, Banten). Jurnal Ilmiah Manajemen Bisnis, 3(02), 205. 
Rares, A., \& Jorie, R. J. (2015). Pengaruh Harga, Promosi, Lokasi, Citra Merek Dan Kualitas Produk Terhadap Keputusan Pembelian Konsumen Di Toko Bengkel Gaoel Manado Town Square. Jurnal Emba, 3(2), 592-604.

Rofiq, A., \& Hufron, M. (2018). Pengaruh Kualitas Produk, Harga Dan Lokasi Terhadap Keputusan Pembelian Di Powernoise Store Studi Kasus Pada Konsumen Powernoise Store Malang. Jurnal Ilmiah Riset Manajemen, 7(02).

Sarwoko, E. (2018). Analisis Statistik Menggunakan SPSS 22 (Malang). Media Nusa Creative.

Setyarko, Y. (2016). Analisis Persepsi Harga, Promosi, Kualitas Layanan, dan Kemudahan Penggunaan Terhadap Keputusan Pembelian Produk Secara Online. Jurnal Ekonomika Dan Manajemen, 5(2), 128-147.

Sugiyono, P. (2011). Metodologi penelitian kuantitatif kualitatif dan REDD. Bandung: Alpabeta.

Swastha, B., \& Sukotjo, I. (2010). Pengantar Bisnis Modern. Yogyakarta: Liberty.

Tjiptono, F., \& Chandra, G. (2011). Service, Quality E Satisfaction Edisi 3. Yogyakarta: Andi Offset.

Wihara, D. S. (2017). Pengaruh Kebijakan Harga dan Lokasi Terhadap Keputusan Pembelian di Agen Pos Wilayah Kota Madiun. JURNAL EKOMAKS, 5(2). 